\title{
Investigation of the effects of different ink density values on color gamut in offset printing
}

\begin{abstract}
A standard color gamut can be obtained with CMYK samples that are printed with an offset printing system according to the ISO 12647-2:2013. It is possible to enhance or widen the color gamut during the printing process by interfering with the density and dot gain characteristics. Printing with a wider color gamut provides a more vivid area and more depth in color. In this study, print trials were conducted at first with standard values (density, dot gain and such). Then another trial was conducted by changing the density values respectively during the trial. Ink density values for all colors were decreased from the standard value as $-0.15 D$, $-0.30 D$ and then increased as $+0.15 D,+0.30 D$. Color gamuts of the trials were calculated and compared at the end. It is found that ink density values directly affect color gamut in offset printing. It is also found that the color gamut decreases equally when ink density values decrease and vice versa. However, some printing problems occurred with high density values even though it gave an expanded color.
\end{abstract}

\section{KEY WORDS}

offset printing, dot gain, solid density, color gamut

\author{
Dogan Tutak (D), \\ Huseyin N. Beytut, \\ Arif Ozcan (1) \\ Marmara University, \\ School of Applied Science, \\ Department of Printing \\ Technologies, Istanbul, Turkey
}

Corresponding author: Dogan Tutak

e-mail:dtutak@marmara.edu.tr

First recieved: 06.03.2017.

Accepted: 06.11.2017.

\section{Introduction}

One of the most important reasons of increased print quality is the use of inks with a high coloring feature (Leach \& Pierce, 1993). The film thickness of the ink should be below $2 \mu \mathrm{m}$ during printing (Dalton et al, 2002). The critical point is the direct effect of ink film thickness on print quality and color gamut. Ink absorption of paper and drying are the other important factors (Zjakić, Bates \& Milković, 2011). It is also very important to have suitable solid ink density values for the used paper surface to achieve the desired print quality and color gamut. When the optimum amount of ink that is transferred onto the paper is set, the print quality as well as the color gamut will increase.

\section{Color Systems and Color Gamut}

The need of developing an international standard that everyone can understand increased as the importance of color increased in the industry. At the beginning of the $20^{\text {th }}$ century, a painter named A.H. Munsell defined the color schemes. The CIE that was established in 1930 explains the base color structure with three coordinates.

There are three elements of color: hue, saturation and brightness Offset printing is a commonly used printing technique where the inked image is transferred from a printing plate to a rubber blanket, then to the printing surface (Ozcan \& Oktav, 2011) and at the same time offset printing is a preferred system in terms of keeping pace with the advancing technology and print quality. Ink density is the first factor that affects the quality. The density impacts color gamut directly. High print density could also cause different print defects (drying and such). Therefore, optimum print density should be obtained in order to get the widest color gamut (Sahinbaskan, 2002).

Hue: The 'attribute of visual sensation according to which an area appears to be similar to one, or to proportions 
of two, of the perceived colors red, yellow, green, and blue.' Looking at an orange, for example, we can see that its color is similar to both red and yellow and we could express its hue as some percentage of each of the two (e.g. 60\% red and 40\% yellow) (Morovič, 2008).

Saturation: is a unique perceptual experience separate from chroma. Like chroma, saturation can be thought of as relative colorfulness. However, saturation is the colorfulness of a stimulus relative to its own brightness, while chroma is colorfulness relative to the brightness of a similarly illuminated area that appears white (Fairchild, 2013).

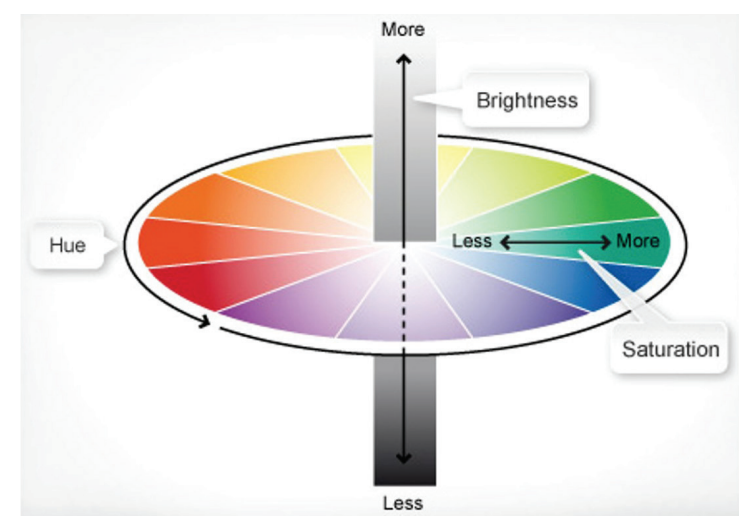

» Figure 1: CIE color gamut

Brightness: The attribute of a visual sensation according to which an area appears to exhibit more or less light.' Returning to the same orange, we can also express this attribute of its color appearance and we would judge it to be higher for parts of it that are directly lit and lower for parts that are in the shade (Morovič, 2008).

CIE color systems places a color to the color gamut with the values of these three components. The $\mathrm{CIE}$ has designed many color models over the years. Although these models differ in the process of technological developments, hue, saturation and brightness are the base components (Sahinbaskan, 2002).

\section{CIE L*a*b*}

The purpose of $\mathrm{CIE}$ is to form a system to enable clear and repeatable production for people who printable produce the color. Forming a universal color template is the target. The important parts of this template are defined as the standard observer and $\mathrm{XYZ}$ color gamut. However unbalanced structure of the $X Y Z$ color gamut has made it difficult to establish the standards (Sahinbaskan, 2002; Tritton 2004).

In 1976, with a view to approximating perceptual uniformity by emulating the nonlinear response of the human eye, the CIE recommended the CIE L*a*b* space (lightness, position between green and magenta and position between blue and yellow) (Rivas et al.,
2011). It works with three basic signals just as in the human eye. These are light-dark, red-green, yellow-blue. $\mathrm{CIE}, \mathrm{CIE} \mathrm{L}^{*} \mathrm{a}^{*} \mathrm{~b}^{*}$ and $\mathrm{CIE} \mathrm{L*} \mathrm{u}^{*} \mathrm{v}^{*}$ are established on the basis of this more uniform detection color system. The balanced L*a*b* color structure was built based on the fact that a color can't be green, red or another color at the same time. Simple values can be used to describe a color. L* represents the lightness, a* represents the red/green value, $b^{*}$ represents the yellow/blue value of the color in the CIE L*a*b* system (Tritton, 2004; Adams \& Weisberg 2000).

$L^{*}$ value determines the brightness from 0 to 100 , meaning how dark or light the color is.

a* positive values determine the redness from 0 to 100. $a^{*}$ negative values determine the greenness from 0 to 100 .

$b^{*}$ positive values determine the yellowness from 0 to 100. $b^{*}$ negative values determine the blueness from 0 to 100 .

CIE L*a*b* is the most commonly used color gamut. Computers and software's used in desktop publishing are based on CIE L*a*b* system.

The following equation is used to obtain the $L^{*} a * b *$ values from the tristimulus values.

$$
\begin{aligned}
& \mathrm{L}^{*}=116(\mathrm{Y} / \mathrm{Yn})^{1 / 3}-16 \\
& \mathrm{a}^{*}=500\left[(\mathrm{X} / \mathrm{Xn})^{1 / 3-}-(\mathrm{Y} / \mathrm{Yn}) \frac{1 / 3}{3}\right] \\
& \mathrm{b}^{*}=200\left[(\mathrm{Y} / \mathrm{Yn})^{1 / 3}-(\mathrm{Z} / \mathrm{Zn}) \frac{1 / 3}{3}\right]
\end{aligned}
$$

$X, Y, Z$ values are the tristumulus values of measured color; $\mathrm{Xn}, \mathrm{Yn}, \mathrm{Zn}$ are the tristimulus values of light (Sahinbaskan, 2002).
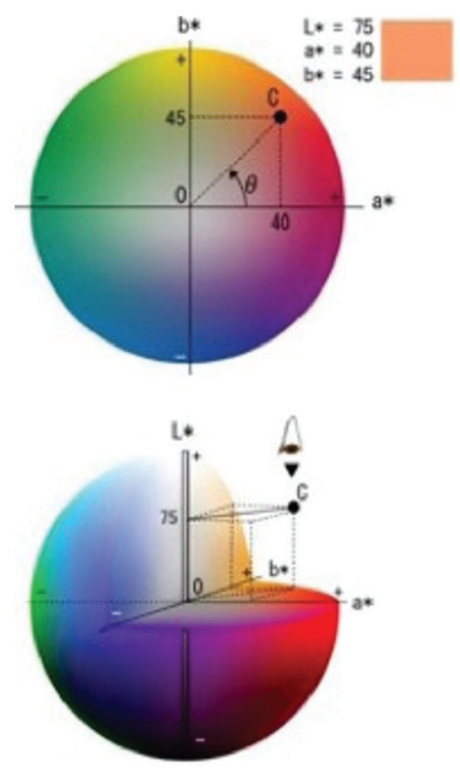

» Figure 2: $C I E L^{*} a^{*} b^{*}$ color gamut model 


\section{Materials and Methods}

In this part of the study, the device and materials that were used for the experiment are summarized. First a test page was created, then print trials were made and finally measurements were conducted and evaluated. Print trials were made on glossy coated paper on a Heidelberg- Printmaster $35 \times 50 \mathrm{~cm}$ printing machine. The printed papers were measured $\mathrm{i} 1 \mathrm{iO}$, and the profiles were created by using X-rite ProfileMaker. The color gamuts made by using the profiles and the differences between them were shown in the tables.

- Printing Machine: Heidelberg-

Printmaster $35 \times 50 \mathrm{~cm}$

- Screen frequency: $70 \mathrm{lpc}$

- CtP: Fujifilm / Vx 6000

- Plate: Fujifilm, Brilla

- Paper: UPM $135 \mathrm{~g} / \mathrm{m}^{2}$ Glossy Paper

- Ink: DYO ink, Standard CMYK

- Density Measurements: GretagMachbeth Spectrophotomer, i1i0

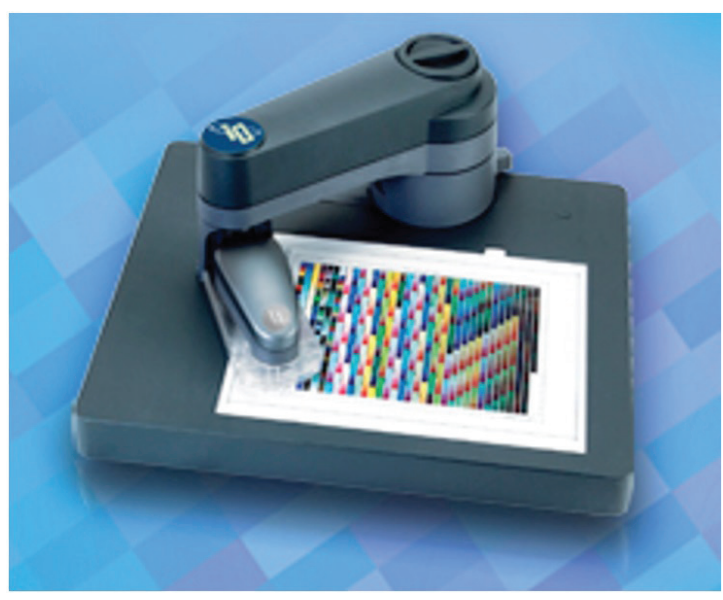

» Figure 3: i1iO Measurement device for test pages

\section{Results and discussion}

\section{Measured Print Values:}

* In editing, ink solid densities-0.30D,-0.15D, +0.15D, $+0.30 \mathrm{D}$ was planned to increase and decrease. However, some fluctuations occurred in these values.

Measured Solid Print Density Values printed on UPM 135 $\mathrm{g} / \mathrm{m}^{2}$ Glossy Paper;

Cyan: $1.49 \mathrm{D}$,

Magenta: $1.43 \mathrm{D}$,

Yellow: $1.41 \mathrm{D}$,

Black: $1.83 \mathrm{D}$
Table 1

ISO 12647-2:2013 standard CMYK and measured L*a*b* values

\begin{tabular}{l|l|l|l}
\hline Color & L & $\mathbf{a}^{*}$ & $\mathbf{b}^{*}$ \\
\hline Cyan & 55 & -37 & -50 \\
\hline Magenta & 48 & 74 & -3 \\
\hline Yellow & 89 & -5 & 93 \\
\hline Black & 16 & 0 & 0 \\
\hline Red & 47 & 68 & 48 \\
\hline Green & 50 & -68 & 25 \\
\hline Blue & 24 & 17 & -46 \\
\hline White Paper & 95 & 0 & -2 \\
\hline Color & L & $\mathbf{a}^{*}$ & $\mathbf{b}^{*}$ \\
\hline Cyan & 58.4 & -35.31 & -50.12 \\
\hline Magenta & 51.08 & 73.02 & -5.41 \\
\hline Yellow & 89.94 & -4.89 & 93.41 \\
\hline Black & 16.48 & 1.02 & 0.52 \\
\hline Red & 49.12 & 66.03 & 48,57 \\
\hline Green & 50.85 & -64.13 & 30.01 \\
\hline Blue & 24.76 & 18.76 & -45.07 \\
\hline White Paper & 94.66 & 0.78 & -4.16 \\
\hline
\end{tabular}

\section{Table 2}

Measured CMYK printing dot gain values printed on UPM $135 \mathrm{~g} / \mathrm{m} 2$ Glossy Paper

\begin{tabular}{l|l|l|l|l}
\hline Original (\%) & Yellow (\%) & Cyan (\%) & Magenta (\%) & Black (\%) \\
\hline 1 & 2 & 2 & 1 & 0 \\
\hline 5 & 10 & 11 & 11 & 9 \\
\hline 10 & 17 & 18 & 18 & 17 \\
\hline 15 & 23 & 25 & 25 & 23 \\
\hline 20 & 30 & 31 & 31 & 30 \\
\hline 25 & 36 & 37 & 37 & 37 \\
\hline 30 & 42 & 44 & 44 & 43 \\
\hline 50 & 53 & 55 & 55 & 54 \\
\hline 60 & 64 & 65 & 65 & 66 \\
\hline 70 & 73 & 73 & 73 & 74 \\
\hline 75 & 82 & 81 & 82 & 83 \\
\hline 90 & 85 & 86 & 85 & 86 \\
\hline 95 & 89 & 89 & 88 & 90 \\
\hline 100 & 95 & 96 & 95 & 96 \\
\hline Density & 1.41 & 1.49 & 1.43 & 1.83 \\
\hline & 98 & 98 & 98 & 99 \\
\hline
\end{tabular}

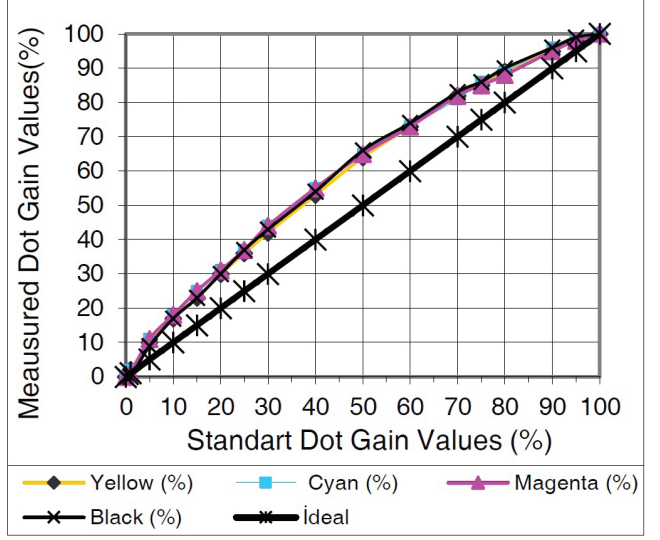

» Figure 4: Measured CMYK printing dot gain curves printed on UPM $35 \mathrm{~g} / \mathrm{m}^{2}$ Glossy Paper 
For the first trial, cyan density values were increased while the other color values were kept same.

Cyan; 1.56 D, 1.69 D, 1.83 D, Other color density values are same.

\section{Table 3}

Measured CMYK printing $\triangle E$ values

\begin{tabular}{l|l|l|l}
\hline \multicolumn{1}{c|}{ Cyan (C) } & Magenta (M) & Yellow (Y) & Black (K) \\
\hline 3.2 & 5.6 & 0.9 & 1.2 \\
\hline
\end{tabular}

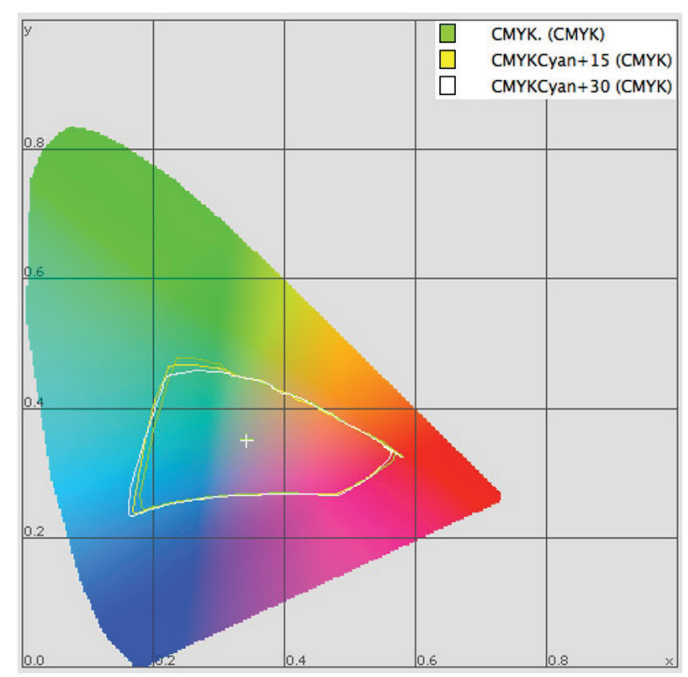

» Figure 5: Cyan ink density values effect on the color gamut

Figure 5 shows that the color gamut increased slightly in comparison with the ISO 12647-2:2013 when cyan density values were increased $+0.15 \mathrm{D}$ and $+0.30 \mathrm{D}$ while the other colors were kept the same.

For the second trial, magenta density values were increased while the other color values were kept the same. Magenta; 1.48 D, 1.67 D, $1.81 \mathrm{D}$, other color density values are same.

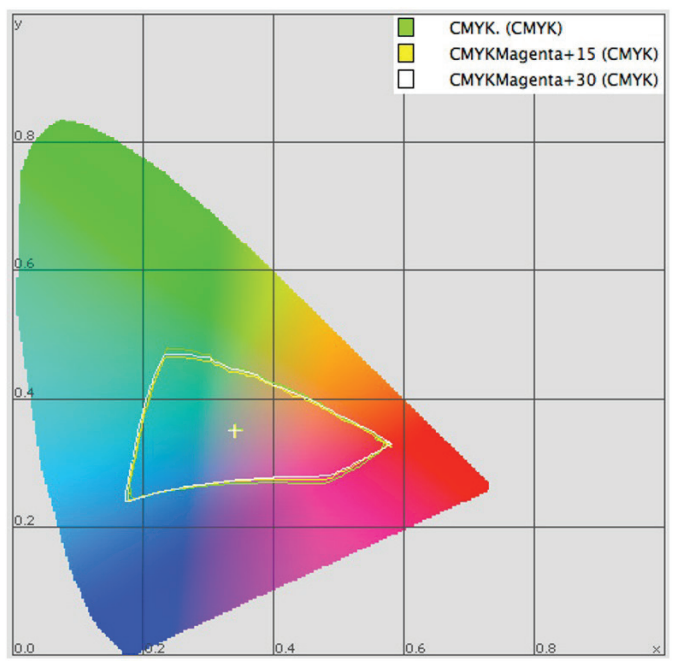

» Figure 6: Magenta ink density values effect on the color gamut
Figure 6 shows that the color gamut did not change in comparison with the ISO 12647-2:2013 when magenta density values were increased $+0.15 \mathrm{D}$ and $+0.30 \mathrm{D}$ while the other colors were kept the same.

For the third trial, yellow density values were increased while the other color values were kept the same. The dot values on the plate were decreased $20 \%$ compared to the standard values.

Yellow; 1.05 D, 1.19 D, 1.37 D, Other color density values are same.

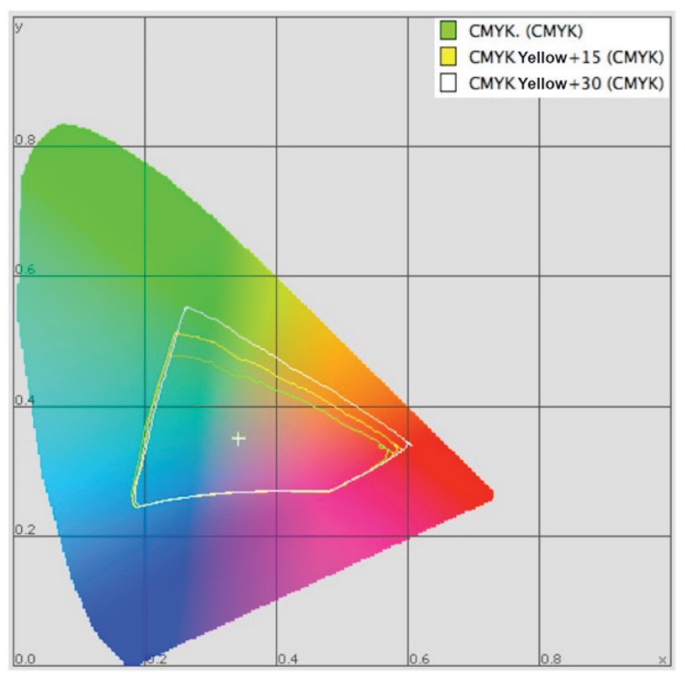

» Figure 7: Yellow ink density values effect on the color gamut

Figure 7 shows that the color gamut was increased in the yellow region in comparison with the ISO 12647-2:2013 when magenta density values were increased $+0.15 \mathrm{D}$ and $+0.30 \mathrm{D}$ while the other colors were kept the same. It was observed that the changed dot values affected the result. For the fourth trial, black density values were increased while the other color values were kept the same.

Black; 1.83 D, 2,08 D, 2.16 D, Other color density values are same.

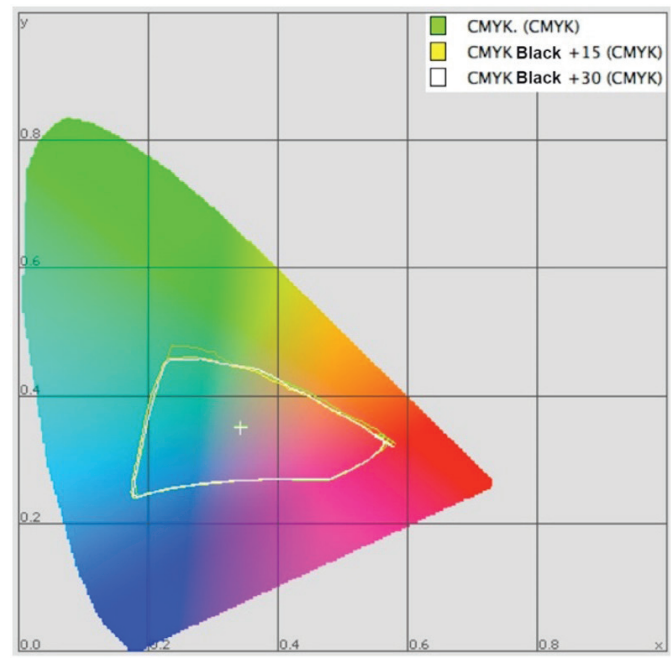

» Figure 8: Black ink density values effect on the color gamut 
Figure 8 shows that the color gamut did not change in comparison with the ISO 12647-2:2013 when magenta density values were increased $+0.15 \mathrm{D}$ and $+0.30 \mathrm{D}$ while the other colors were kept the same.

Density values of all colors were changed in certain proportions and color gamuts were compared to each other.

For the fifth trial, all color density values were increased first +0.15D and +0.30D, then decreased-0.15D and $-0.30 \mathrm{D}$ compared to the ISO 12647-2.

When increase and decrease measured CMYK density values

Cyan; 1.28 D, $1.41 \mathrm{D}, 1.48 \mathrm{D}, 1.67 \mathrm{D}, 1.89 \mathrm{D}$

Magenta; $1.18 \mathrm{D}, 1.31 \mathrm{D}, 1.42 \mathrm{D}, 1.61 \mathrm{D}, 1.78 \mathrm{D}$

Yellow; 1.21 D, $1.32 \mathrm{D}, 1.43 \mathrm{D}, 1.58 \mathrm{D}, 1.75 \mathrm{D}$

Black; 1.53 D, 1.68 D, 1.81 D, 1,98 D, 2.07 D

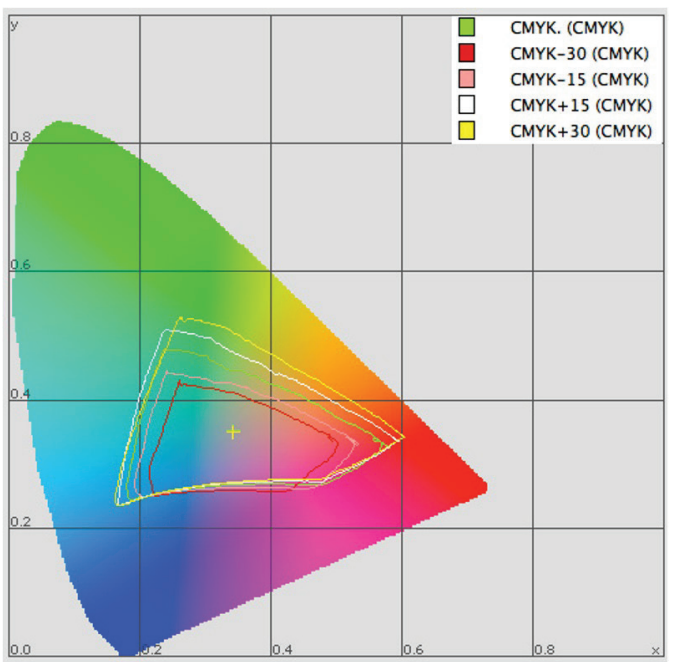

» Figure 9: $-0.30 D$ and +0.300 density values effect on the color gamut

Figure 9 shows the effect of the changed density values on the color gamut. The green color gamut represents the ISO 12647-2. The color gamut obtained with +0.15D and $+0.30 \mathrm{D}$ CMYK density values is wider. The white gamut represents $+0.15 \mathrm{D}$ density values; the yellow gamut represents $+0.30 \mathrm{D}$ density values. The color gamut decreased when the density was decreased-0.15D and $-30 \mathrm{D}$. The pink gamut represents-0.15D the red gamut represents-0.30D density values.

When we increased the solid tone density from $-30 D$ to $+30 D$, the color gamut was expanded.

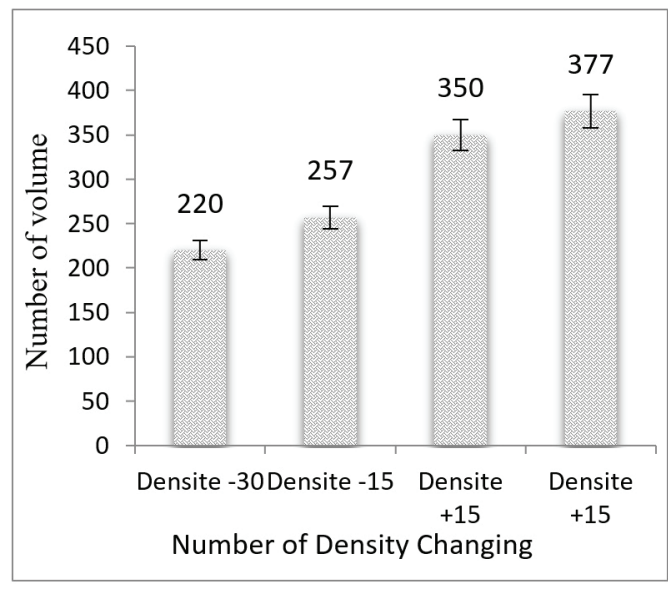

» Figure 10: ISO 12647-2 standard CMYK color gamut volume diagram

\section{Conclusions}

It is found that ink density values directly affect color gamut in offset printing. It is also found that the color gamut decreases equally when ink density values decrease and vice versa.

However, some printing problems occurred with high density values even though it gave an expanded color gamut. The problems were delay in ink setting, set-off and blocking. Even though the color gamut is important, it is more essential to use optimum ink density values to have a trouble-free printing process.

\section{References}

Adams R. M. \& Weisberg J.B. (2000) The GATF Practical Guide to Color Management. Pittsburgh, GATFPress.

Dalton, J. S., Preston, J. S., Heard, P. J., Allen, G. C., Elton, N. J. \& Husband, J. C. (2002) Investigation into the Distribution of Ink Components Trough Printed Coated Paper: Part 2. Utilising XPS and SIMS. Colloids and Surfaces A: Physicochemical and engineering Aspects. 205 (3), 199-213. Available from: doi: 10.1016/ S0927-7757(02)00021-3 [Accessed 21th May 2017].

Fairchild, M. D. (2013) Color Appearance Models. 3rd ed. Chichester, Wiley.

Leach, R. H. \& Pierce, R. J. (eds.) (1993) The Printing Ink Manual. 5th ed. Springer, London.

Morovič, J.(2008) Color Gamut Mapping. New York, Wiley. Ozcan, A. \& Oktav, M. (2011) Comparison of Brightness and Colour Characteristics of Mineral and Vegetable Oil-based Offset Printing Ink. Asian Journal of Chemistry. 23 (6), 2685-2687. Available from: https:// www.researchgate.net/publication/266261171_Comparison_of_Brightness_and_Colour_Characteristics_of_Mineral_and_Vegetable_Oil-Based_ Offset_Printing_Ink [Accessed 23rd May 2017]. 
Rivas, T., Matías, J. M., Taboada, T. \& Ordóñez, C.

(2011) Functional Experiment Design for the Analysis of Colour Changes in Granite Using New L* $a^{*}$ b* Functional Colour Coordinates. Journal of Computational and Applied Mathematics. 235 (16), 4701-4716. Available from: doi: 10.1016/j. cam.2010.08.005 [Accessed 23rd May 2017].

Sahinbaskan, T. (2002) Determination of The Color Separation Parameters in Desktop Publishing System. PhD thesis. Marmara University Istanbul. Tritton, K. (2004) Fundamentals of Colour and Colour Vision. Pira International. U.K.

Zjakić, I., Bates, I. \& Milković, M. (2011) A Study of Dot Gain and Gamut for Prints Made with Highly Pigmented Inks. Tehnički vjesnik / Technical Gazette. 18 (2), 227-235. Available from: https://pdfs.semanticscholar.org/9a96/857e3181f62a17e59f634827b40f91bfda1f.pdf? ga $=2.152882810 .2146654962 .1523622570-$ 1430097508.1523622570 [Accessed 24th May 2017].

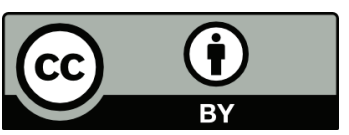

(C) 2018 Authors. Published by the University of Novi Sad, Faculty of Technical Sciences, Department of Graphic Engineering and Design. This article is an open access article distributed under the terms and conditions of the Creative Commons Attribution license 3.0 Serbia (http://creativecommons.org/licenses/by/3.0/rs/). 